\title{
PENGARUH MODEL PEMBELAJARAN PROBLEM POSING TIPE WITHIN SOLUTION POSING TERHADAP HASIL BELAJAR MATEMATIKA SISWA KELAS VIII SMP NEGERI 13 KOTA BENGKULU
}

\author{
${ }^{1}$ Padilah Ulfah, ${ }^{2}$ Effie Efrida Muchlis, ${ }^{3}$ Della Maulidiya \\ ${ }^{1,2,3}$ Program Studi Pendidikan Matematika JPMIPA FKIP Universitas Bengkulu \\ email: ${ }^{1}$ padilahd978@gmail.com, ${ }^{2}$ effie_efrida@unib.ac.id, ${ }^{3}$ della.maulidiya@unib.ac.id
}

\begin{abstract}
Abstrak
Penelitian ini bertujuan untuk mengetahui pengaruh model pembelajaran problem posing tipe within solution posing terhadap hasil belajar siswa. Penelitian ini merupakan penelitian eksperimen semu dengan populasi seluruh peserta didik kelas VIII SMPN 13 Kota Bengkulu Semester Genap Tahun Ajaran 2017/2018. Sampel diperoleh kelas VIII E sebagai kelas eksperimen dengan peserta didik yang berjumlah 34 peserta didik yang mendapat perlakuan model pembelajaran problem posing tipe within solution posing dan kelas VIII D sebagai kelas kontrol dengan peserta didik yang berjumlah 34 peserta didik yang mendapat perlakuan model pembelajaran ekspositori. Nilai rata-rata hasil posttest kelas eksperimen 66,41 dan rata-rata posttest kelas kontrol adalah 56,82. Berdasarkan hasil analisis data menggunakan uji-t dengan taraf nyata $(\alpha)=10 \%$ diperoleh nilai Sig. $=0,02$, sehingga Sig. $<\alpha$. Oleh karena itu, dapat disimpulkan bahwa ada pengaruh model pembelajaran problem posing tipe within solution posing terhadap hasil belajar matematika siswa di kelas VIII SMP Negeri 13 Kota Bengkulu.

Kata Kunci : Model pembelajaran problem posing tipe within solution posing, pembelajaran ekspositori, hasil belajar peserta didik.
\end{abstract}

\begin{abstract}
This research has purpose for knowing effect problem posing type within solution posing learning models to learning results. This study is a quasi-experimental research with the population was all of the grade VIII students of SMPN 13 Bengkulu academic year 2017/2018. Sample that choosed is student class VIII E as a experiment group with and student class VIII D as a control group. Average value of learning achievements of students in the experiment group 66,41 andcontrol group 56,82. Based on the results of data analysis obtained value Sig. $=0,02$ with $\alpha=10 \%$, so that Sig. $<\alpha$. Therefore, can be concluded that there is an influence of problem posing type within solution posing learning models against the results of learning mathematics students in grade VIII SMP 13 Bengkulu City.
\end{abstract}

Keywords : problem posing type within solution posing learning models, ekspositori learning, results of mathematics learning of students.

\section{PENDAHULUAN}

Matematika mempunyai peranan yang sangat penting bagi perkembangan berbagai disiplin ilmu. Matematika juga mampu melatih kemampuan daya pikir manusia. Matematika dapat berguna untuk memecahkan berbagai masalah dalam kehidupan sehari-hari. Hal ini membuat matematika tidak dapat lepas dari kehidupan manusia.

$$
\text { Gagne (dalam Dahar 2011:2) }
$$

mengemukakan belajar dapat didefinisikan sebagai suatu proses di mana suatu organisasi berubah perilakunya sebagai akibat pengalaman. Pembelajaran matematika di 
sekolah bertujuan untuk mempersiapkan peserta didik agar mampu menyelesaikan masalah matematika dalam kehidupan seharihari. Namun matematika terkadang dianggap pelajaran yang tidak mudah dipahami dan membosankan sehingga membuat peserta didik kurang memperhatikan saat guru menerangkan pelajaran. Kondisi seperti ini timbul karena kurangnya motivasi siswa untuk mengikuti pelajaran dengan baik.

Berdasarkan wawancara dengan salah satu guru matematika di kelas VIII SMP Negeri 13 Kota Bengkulu bahwa dalam pembelajaran matematika siswa kurang memiliki motivasi untuk terlibat dalam proses belajar mengajar. Siswa kurang aktif dalam mengikuti proses pembelajaran. Terlihat dalam proses pembelajaran, siswa terkadang hanya menerima tanpa memiliki rasa ingin tahu tentang materi yang diajarkan. Siswa juga kurang memiliki rasa percaya diri dalam hal bertanya berkaitan dengan penjelasan guru yang kurang dipahami. Sehingga materi yang diajarkan guru tidak sampai pada siswa. Hal ini tentunya berimbas pada hasil belajar siswa.

Pembelajaran matematika di sekolah, tidak lepas dari model pembelajaran yang dirancang oleh guru demi mencapai suatu pembelajaran yang terarah. Model pembelajaran adalah kerangka konseptual yang melukiskan prosedur yang sistematis dalam mengorganisasikan pengalaman belajar untuk mencapai tujuan belajar tertentu (Taufik \& Muhammadi, 2011:1). Tugas guru adalah memilih dan merancang model pembelajaran sehingga lebih terarah untuk diterapkan di kelas.

Dalam upaya mengatasi permasalahan di atas, perlu diterapkan model pembelajaran yang variatif. Model pembelajaran yang dapat memicu peserta didik untuk termotivasi dalam belajar dan siswa dapat berperan aktif dalam proses pembelajaran. Salah satu model yang dapat diterapkan adalah model problem posing yang dalam pelaksanaannya menuntut siswa untuk berpikir aktif serta dapat meningkatkan kemampuan berpikir. Jika siswa dapat mengikuti pembelajaran dengan baik tentunya dapat meningkatkan hasil belajar siswa.

Model pembelajaran problem posing merupakan model pembelajaran yang mengharuskan siswa menyusun pertanyaan sendiri atau memecah suatu soal menjadi pertanyaan-pertanyaan yang lebih sederhana yang mengacu pada penyelesaian soal tersebut (Thobroni 2016:287). Model pembelajaran ini diharapkan mampu memicu siswa berpikir kritis dan kreatif tentunya dalam mencari solusi dari pemecahan soal nantinya. Problem posing terbagi menjadi 3 yaitu pre-solution posing, within solution posing, dan postsolution posing. Menurut Thobroni (2016:288) within solution posing yaitu jika seorang siswa mampu merumuskan ulang pertanyaan soal tersebut menjadi sub-sub pertanyaan baru yang urutan penyelesaiannya seperti yang telah diselesaikan sebelumnya.

Problem posing memiliki tiga tipe yang ketiganya mempunyai langkah-langkah pembelajaran yang sama. Perbedaan dari ketiga tipe tersebut hanya pada kondisi permasalahan yang diberikan. Suryosubroto dalam Guntara dkk (2014) menyatakan bahwa langkahlangkah pembelajaran problem posing yaitu:

1) Guru membuka kegiatan pembelajaran.

2) Menyampaikan tujuan pembelajaran

3) Guru menjelaskan materi pelajaran kepada para siswa

4) Guru memberikan latihan soal secukupnya

5) Memberikan kesempatan kepada siswa untuk bertanya tentang hal-hal yang belum jelas

6) Guru membentuk kelompok-kelompok belajar yang heterogen, tiap kelompok terdiri atas 4-5 siswa

7) Siswa diminta mengajukan 1 atau 2 buah soal berdasarkan informasi yang diberikan guru, dan siswa yang bersangkutan harus mampu menyelesaikannya

8) Guru memberikan tugas rumah secara individu sebagai penguatan

9) Guru menutup kegiatan pembelajaran 
Pembelajaran ekspositori merupakan strategi pembelajaran yang menekankan pada proses penyampaian materi secara verbal dari seorang guru kepada sekelompok siswa dengan maksud agar siswa dapat menguasai materi pelajaran secara optimal, materi pelajaran langsung disampaikan oleh guru, siswa tidak dituntut untuk menemukan materi tersebut (Majid, 2013: 216). Pada awal pembelajaran, guru menjelaskan materi dan contoh-contoh soal disini juga terjadi proses bertanya jawab dengan guru.

Menurut Dimyati dan Mudjiono (2013:3), hasil belajar adalah akhir dari suatu proses belajar dimana didalamnya terdapat interaksi tindak belajar dan tindak mengajar. Klasifikasi hasil belajar yang dikemukakan Benyamin Bloom secara garis besar terbagi menjadi tiga ranah, yakni ranah kognitif, ranah afektif, dan ranah psikomotorik (Sudjana, 2016: 22-23).

\section{METODE}

Jenis penelitian yang digunakan dalam penelitian ini adalah quasy exsperiment atau eksperimen semu. Desain eksperimen semu mempunyai kelompok kontrol, tetapi tidak dapat berfungsi sepenuhnya untuk mengontrol variabel-variabel luar yang mempengaruhi pelaksanaan eksperimen (Lestari dan Yudhanegara, 2017: 136).

Populasi dalam penelitian ini dalah seluruh siswa kelas VIII SMP Negeri 13 Kota Bengkulu tahun ajaran 2017/2018. Pada kelas sampel pertama (kelas eksperimen) pembelajaran dilaksanakan dengan menggunakan model pembelajaran problem posing tipe within solution posing dan pada kelas sampel kedua (kelas kontrol) pembelajaran dilaksanakan dengan pembelajaran ekspositori.

Instrumen dalam penelitian ini adalah lembar tes hasil belajar siswa. Lembar tes hasil belajar yang diberikan adalah lembar tes akhir (posttest) yang diberikan dalam bentuk soal tes essay atau uraian. Sebelum posttest digunakan, dilakukan analisis item dengan uji validitas, reliabilitas, daya pembeda, dan taraf kesukaran.

Teknik yang digunakan untuk mengukur validitas soal dengan teknik kolerasi product moment rumusnya adalah:

$$
r_{x y}=\frac{N \sum X Y-\left(\sum X\right)\left(\sum Y\right)}{\sqrt{\left(N \sum X^{2}-\left(\sum X\right)^{2}\right\}\left[N \sum Y^{2}-\left(\sum Y\right)^{2}\right]}}
$$

Sumber : Jihad dan Haris (2013 : 180)

Rumus yang digunakan untuk menentukan reliabilitas instrument adalah sebagai berikut:

$$
r_{11}=\left(\frac{n}{n-1}\right)\left(1-\frac{S_{i}^{2}}{S_{t}^{2}}\right)
$$

Sumber : Jihad dan Haris (2013 : 180)

Rumus yang digunakan untuk uji taraf kesukaran :

$$
I K=\frac{\overline{\mathrm{X}}}{\mathrm{SMI}}
$$

Sumber : Lestari danYudhanegara (2017: 224)

Untuk menentukan daya pembeda, rumus yang digunakan adalah :

$$
D P=\frac{\overline{\mathrm{X}}_{\mathrm{A}}-\overline{\mathrm{X}}_{\mathrm{B}}}{\mathrm{SMI}}
$$

Sumber : Lestari danYudhanegara(2017 : 217)

Sebelum dilakukan pengujian hipotesis, maka terlebih dahulu dilakukan uji prasyarat analisis, yaitu sebagai berikut:

Pengujian normalitas dilakukan untuk mengetahui normal tidaknya suatu distribusi data, dengan hipotesis :

$H_{0}$ : Data berdistribusi normal

$H_{1}$ : Data tidak berdistribusi normal

Kriteria pengujiannya adalah $H_{0}$ diterima jika Sig. > 0,05. Pada penelitian ini uji normalitas menggunakan uji Kolmogorov Smirnov Z berbantuan spss 16 .

Uji homogenitas dilakukan untuk mengetahui apakah varians data dari sampel yang dianalisis homogen atau tidak (Lestari \& Yudhanegara, 2017 : 248). Pengujian homogenitas varians menggunakan uji $F$, dengan rumus berikut:

$$
F=\frac{\text { Varians terbesar }}{\text { Varians terkecil }}
$$

Sumber : Sugiyono, 2017:140

Padila, Effie, Della

Pengaruh Model Pembelajaran Problem Posing Tipe Within Solution Posing Terhadap Hasil Belajar Matematika Siswa Kelas VIII SMP Negeri 13 Kota Bengkulu 
Kriteria pengujian uji homogenitas adalah jika harga $\mathrm{F}$ hitung kurang dari atau sama dengan $\mathrm{F}$ tabel ( $\left.\mathrm{F}_{\text {hitung }} \leq \mathrm{F}_{\text {tabel }}\right)$, maka kedua kelompok sampel bersifat homogen.

Pengujian hipotesis data berdistribusi normal, menggunakan rumus uji-t, jika variansi homogen :

$t_{\text {hitung }}=\frac{\overline{X_{1}}-\overline{X_{2}}}{S_{\text {gabungan } \sqrt{\frac{n_{1}+n_{2}}{n_{1} \cdot n_{2}}}}}$

Sumber : Lestari dan Yudhanegara (2017 : 282) dengan

$S_{\text {gabungan }}=\sqrt{\frac{\left(n_{1}-1\right) s_{1}{ }^{2}+\left(n_{2}-1\right) s_{2}{ }^{2}}{n_{1}+n_{2}-2}}$

Sumber : Lestari dan Yudhanegara (2017 : 282)

PengujianHipotesis

$H_{0}: \mu_{1} \leq \mu_{2}$

$H_{1}: \mu_{1}>\mu_{2}$

atau

$H_{0}$ : Hasil belajar matematika siswa dengan model pembelajaranproblem posing tipe within solution posingkurang dari sama dengan hasil pembelajaran ekspositori di kelas VIII SMP Negeri 13 Kota Bengkulu.

$H_{1}$ : Hasil belajar matematika siswa dengan model pembelajaran problem posing tipe within solution posing lebih dari hasil belajar dengan pembelajaran ekspositori di kelas VIII SMP Negeri 13 Kota Bengkulu.

Pada penelitian ini pengujian hipotesis, menggunakan bantuan spss $16 . \mathrm{H}_{0}$ diterima jika Sig. $>\alpha . \mathrm{H}_{0}$ ditolak jika Sig. $<\alpha$.

\section{HASIL DAN PEMBAHASAN}

\section{Hasil uji validitas}

Tabel 1. Hasil Uji Validitas Instrumen

\begin{tabular}{|c|c|c|c|c|c|c|c|c|}
\hline \multirow{2}{*}{$\begin{array}{l}\text { Bufir } \\
\text { Soll }\end{array}$} & \multicolumn{2}{|c|}{ Väțit: } & \multirow{2}{*}{$\begin{array}{l}\text { Refiabdits } \\
\text { Belintelits }\end{array}$} & \multicolumn{2}{|c|}{ Tirgtest Kesikeran } & \multicolumn{2}{|c|}{ Dryz Peabeda } & \multirow{2}{*}{ KETERAVGAY } \\
\hline & $\mathrm{B} \pi \mathrm{r}$ & Ket & & Injets & Eeterngen & $\mathrm{Dp}$ & Eeterngen & \\
\hline 1 & 0,79 & Vaid & \multirow{5}{*}{$\begin{array}{c}\text { B.1 }=0.74 \\
\text { (Ting) }\end{array}$} & 0,49 & Seden? & 0,21 & Cuktọ & Dignakin \\
\hline 2 & 0,63 & viid & & 0,70 & Sedeng & 0,35 & Oilup & Dignim \\
\hline 3 & 0,64 & vild & & 0,44 & Secton & 0,26 & Cistp & Dignimin \\
\hline 4 & 0,85 & viid & & 0,32 & Stèns & 0,62 & Buiz & Dignม่ม1 \\
\hline 5 & 0,60 & vild & & 0.34 & Secten? & 0.26 & Cilsp & Dignakn \\
\hline
\end{tabular}

Jadi, semua soal (nomor 1 sampai dengan 5) dapat digunakan.

\section{Uji Normalitas}

Uji normalitas data dilakukan dengan menggunakan bantuan spss, adapun hipotesisnya adalah sebagai berikut:

$\mathrm{H}_{0}$ : data hasil belajar kelas berdistribusi normal $\mathrm{H}_{1}$ : data hasil belajar kelas berdistribusi tidak normal

Kriteria pengujiannya adalah jika Sig $>\alpha(0,1)$ maka $\mathrm{H}_{0}$ diterima. Dari hasil perhitungan, diperoleh hasil uji statistik dengan menggunakan spss sebagai berikut:

Tabel 2. Hasil uji normalitas

\begin{tabular}{|c|c|c|c|c|c|c|}
\hline \multicolumn{7}{|c|}{ Tests of (thmally } \\
\hline & \multicolumn{3}{|c|}{ Kolmbo:ror:Smimop } & \multicolumn{3}{|c|}{ Sharainirik } \\
\hline & Statstos: & if & Sill & Strtist: & af & So \\
\hline KELSKONTROL & 108 & 34 & 20 & .66 & 34 & 405 \\
\hline KELSE EKSTERMEN & .077 & 34 & 20 & .878 & 34 & 611 \\
\hline
\end{tabular}

Pada tabel di atas, dapat dilihat bahwa nilai Sig. yang diperoleh sebesar 0,2. Karena nilai Sig. $>\alpha$, maka $\mathrm{H}_{0}$ diterima. Pada kelas eksperimen nilai Sig. diperoleh 0,2 . Karena nilai Sig. $>\alpha$, maka $\mathrm{H}_{0}$ diterima. Sehingga data hasil belajar kelas kontrol dan kelas eksperimen berdistribusi normal.

\section{Uji Homogenitas}

Uji homogenitas pada penelitian ini menggunakan uji kesamaan dua varians. Adapun hipotesisnya sebagai berikut :

$H_{0}$ : Varians homogen

$H_{1}$ : Varians tidak homogen

Pengujian homogenitas varians menggunakan uji F, dengan rumus berikut:

$F=\frac{\text { Varians terbesar }}{\text { Varians terkecil }}$

(Sugiyono, 2017:140)

$$
\begin{aligned}
& F=\frac{180,734}{105,18}=1,71833 \\
& \mathrm{~F}_{\text {tabel }}=\mathrm{F}_{(0,1 ; 33 ; 33)}=1,570591
\end{aligned}
$$

Kriteria pengujian uji homogenitas adalah jika harga $\mathrm{F}$ hitung kurang dari atau sama dengan $\mathrm{F}$ tabel $\left(\mathrm{F}_{\text {hitung }} \leq \mathrm{F}_{\text {tabel }}\right)$, maka kedua kelompok sampel bersifat homogen dan sebaliknya jika $F$

Padila, Effie, Della

Pengaruh Model Pembelajaran Problem Posing Tipe Within Solution Posing Terhadap Hasil Belajar Matematika Siswa Kelas VIII SMP Negeri 13 Kota Bengkulu 
hitung lebih dari $\mathrm{F}$ tabel $\left(\mathrm{F}_{\text {hitung }}>\mathrm{F}_{\text {tabel }}\right)$ maka kedua kelompok sampel tidak homogen. Pada hasil perhitungan, didapat $F_{\text {hitung }}<F_{\text {tabel }}$ yang artinya kedua kelompok sampel bersifat homogen.

Dengan berbantuan spss juga didapat kedua sampel bersifat homogen, sebagai berikut: Kriteria pengujian hipotesis adalah terima $\mathrm{H}_{0}$ jika Sig. $>\alpha$

\section{Tabel 3. Hasil Uji Homogenitas}

Test of Homogeneity of Variances

HASU BELAJAR MATEMATIKA
\begin{tabular}{|c|c|c|c|}
\hline $\begin{array}{c}\text { Levene } \\
\text { Statistic }\end{array}$ & $\mathrm{df1}$ & $\mathrm{d} 2$ & Siq. \\
\hline 1.282 & 1 & 66 & .262 \\
\hline
\end{tabular}

Berdasarkan tabel 3. dapat dilihat bahwa nilai Sig. sebesar 0,262 dan nilai $\alpha=0,1$, karena Sig. $>\alpha$ maka $H_{0}$ diterima yang berarti data homogen.

\section{Pengujian Hipotesis}

Dari hasil uji statistik dengan menggunakan spssdidapat Sig. Sebesar 0,02. Karena nilai Sig. $<\alpha$, maka $\mathrm{H}_{0}$ ditolak. Sehingga $\mathrm{H}_{1}$ diterima artinya hasil belajar matematika siswa dengan model pembelajaran problem posing tipe within solution posing lebih dari hasil belajar matematika dengan pembelajaran ekspositori di kelas VIII SMP Negeri 13 Kota Bengkulu. Terdapat perbedaan antara hasil belajar kelas eksperimen dan kelas kontrol yaitu rata-rata kelas eksperimen 66,41 sedangkan kelas kontrol 56,82. Sehingga terdapat pengaruh dari model pembelajaran problem posing tipe within solution posing.

\section{PEMBAHASAN}

\section{Analisis Proses Belajar}

Proses pembelajaran pada kelas eksperimen dilaksanakan sebanyak 6 pertemuan, tidak termasuk posttest. Pada tahap awal proses pembelajaran, peneliti menyampaikan tujuan pembelajaran dan memotivasi peserta didik dengan menghubungkan materi pembelajaran dengan kehidupan sehari-hari. Selanjutnya, peneliti menyampaikan materi dan memberikan contoh pengerjaan soal sesuai model pembelajaran problem posing tipe within solution posing. Kemudian peserta didik diminta mengerjakan Lembar Soal. Peserta didik diminta untuk mengerjakan Lembar Soal secara berkelompok. Gambar di bawah ini merupakan contoh jawaban peserta didik di Lembar Soal pada pertemuan ke-1.

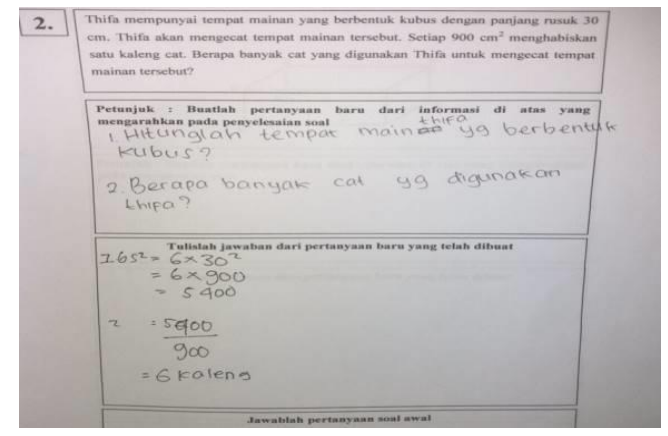

Gambar 1. Contoh Jawaban Peserta Didik di Lembar Soal Nomor 2 Pertemuan ke-1

Terlihat bahwa peserta didik sudah mencoba membuat pertanyaan baru yang mengarahkan ke soal awal. Namun bentuk pertanyaan baru siswa masih belum tepat. Kemudian pada petunjuk akhir yaitu siswa diminta menjawab pertanyaan soal awal, namun belum dijawab oleh siswa.

Gambar di bawah ini merupakan contoh jawaban peserta didik di Lembar Soal pada pertemuan ke-5.

Gambar 2. Contoh Jawaban Peserta Didik di Lembar Soal Nomor 1 Pertemuan ke-5

Pada pertemuan kelima, peserta didik mengerjakan Lembar Soal tentang materi volume prisma. Terlihat bahwa peserta didik telah mengerjakan semua tahap yang diberikan.

Padila, Effie, Della

Pengaruh Model Pembelajaran Problem Posing Tipe Within Solution Posing Terhadap Hasil Belajar Matematika Siswa Kelas VIII SMP Negeri 13 Kota Bengkulu 
Siswa telah membuat pertanyaan baru dan mengerjakan setiap petunjuk yang diberikan.

Proses pembelajaran pada kelas kontrol dilaksanakan sebanyak 6 pertemuan, tidak termasuk posttest. Pada tahap awal proses pembelajaran, peneliti menyampaikan tujuan pembelajaran dan memotivasi peserta didik dengan menghubungkan materi pembelajaran dengan kehidupan sehari-hari. Menyampaikan materi menggunakan metode ekspositori. Kemudian peserta didik diminta mengerjakan Lembar Kerja Siswa. Peserta didik diminta untuk mengerjakan LKS secara individu.

Gambar di bawah ini merupakan contoh jawaban peserta didik di LKS pertemuan ke-1

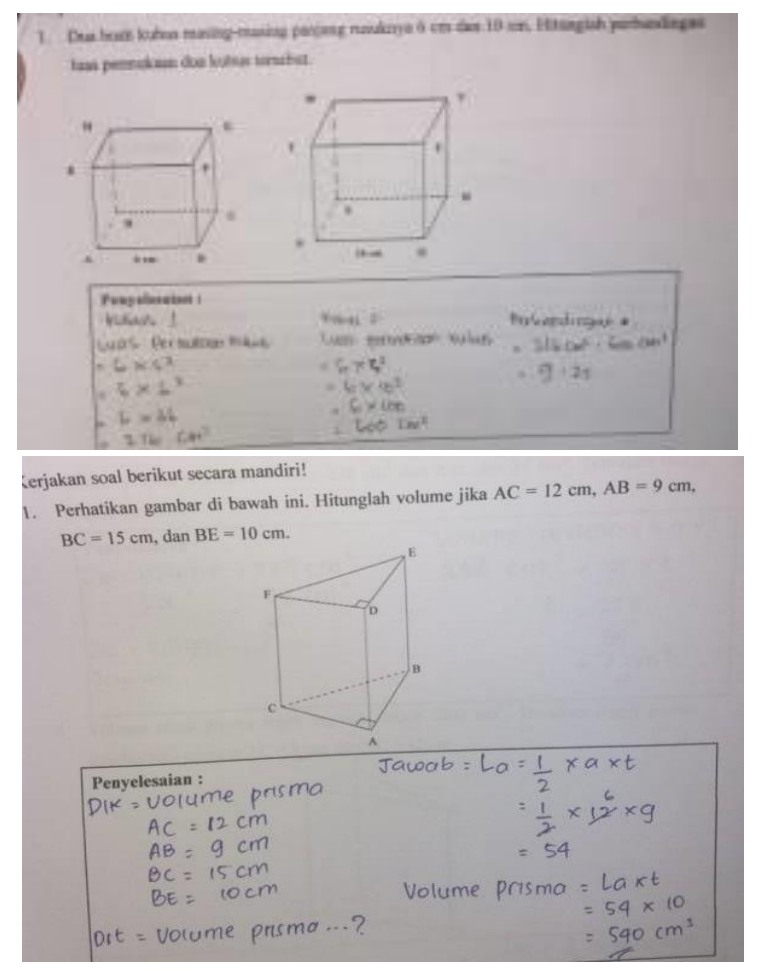

Gambar 3. Contoh Jawaban Peserta Didik pada LKS No 1 Pertemuan ke-1

Gambar di atas merupakan contoh dari salah satu jawaban peserta didik yang menjawab dengan benar. Dapat dilihat bahwa peserta didik menjawab sesuai dengan pertanyaan.

Gambar di bawah ini merupakan contoh jawaban peserta didik di LKS No 2 pertemuan ke-1.

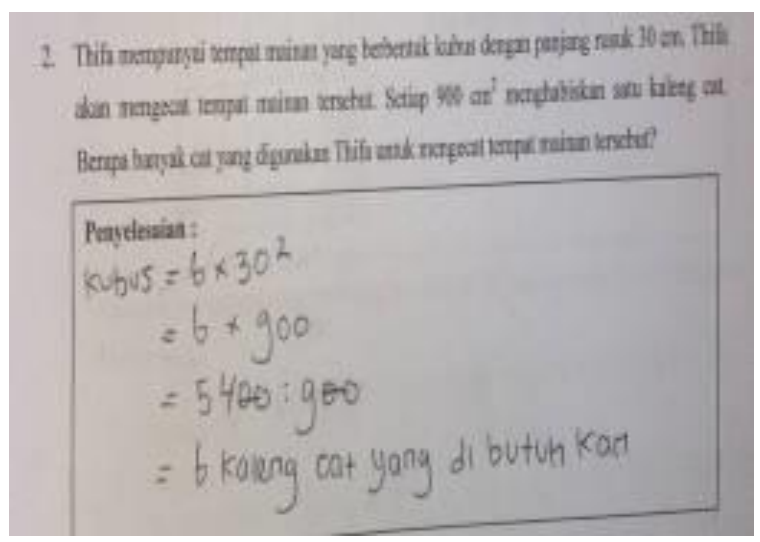

Gambar 4.Contoh Jawaban Peserta Didik pada LKS Nomor 2 Pertemuan ke-1

Terlihat bahwa peserta didik sudah menjawab pertanyaan dengan benar, namun jawaban belum rinci seperti tidak menuliskan rumus terlebih dahulu.

Gambar di bawah ini merupakan contoh jawaban peserta didik di LKS pertemuan ke-5.

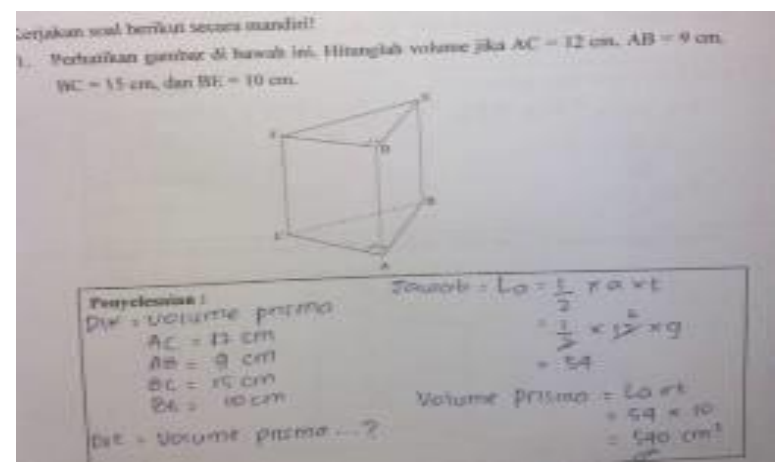

Gambar 5. Contoh Jawaban Peserta Didik pada LKS Nomor 1 Pertemuan ke-5

Pada pertemuan kelima, peserta didik mengerjakan LKS tentang materi volume prisma. Terlihat bahwa peserta didik telah mengerjakan dengan benar, mulai dari menuliskan diketahui dan lengkap dengan rumus dari menghitung volume prisma.

Hasil penelitian ini menunjukkan bahwa terdapat perbedaan antara hasil belajar peserta didik yang menggunakan model pembelajaran Problem Posing tipe Within Solution Posing dan hasil belajar peserta didik yang menggunakan metode ekspositori di kelas VIII SMP N 13 Kota Bengkulu semester genap 
dengan materi luas permukaan dan volume kubus, balok, prisma, limas.

Gambar di bawah ini merupakan contoh jawaban peserta didik kelas eksperimen pada soal posttes

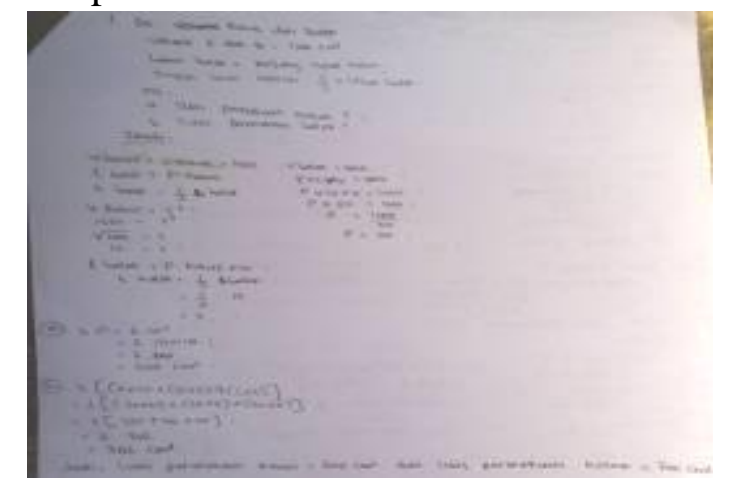

Gambar 6. Contoh Jawaban Nomor 1 Posttest siswa kelas Eksperimen

Gambar di atas adalah contoh jawaban nomor 1 posttest salah satu siswa kelas eksperimen. Terlihat dari jawaban siswa tersebut, siswa mengerjakan dengan bertahap dan menjawab dengan lengkap beserta kesimpulan pertanyaan soal. Pada jawaban siswa tersebut, siswa dapat menghitung lebar balok dan tinggi balok yang belum diketahui. Dengan menghitung panjang rusuk kubus terlebih dahulu kemudian siswa dapat menghitung lebar dan tinggi balok.

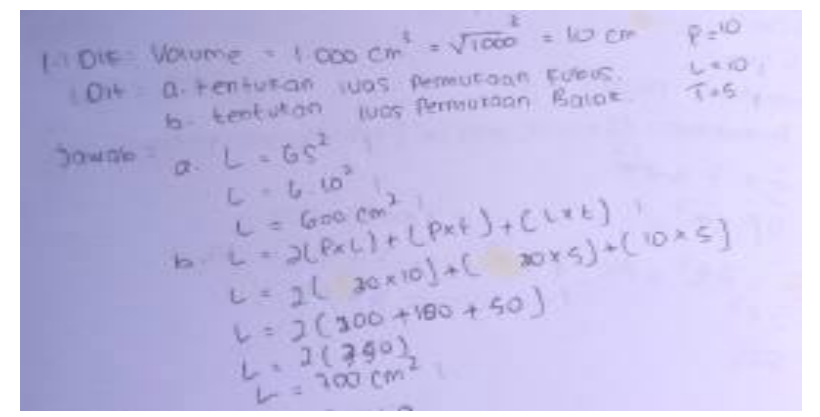

Gambar 7. Contoh Jawaban Nomor 1 Posttest siswa kelas Kontrol

Gambar di atas adalah contoh jawaban nomor 1 posttest salah satu siswa kelas kontrol. Terlihat dari jawaban siswa tersebut, siswa mengerjakan dengan langsung menjawab pertanyaan soal namun tidak membuat darimana angka tersebut didapatkan. Siswa tidak membuat perhitungan dari tinggi balok yang didapatnya yaitu $5 \mathrm{~cm}$. Tidak seperti pada jawaban kelas eksperimen tadi yang menuliskan karena tinggi balok $=\frac{1}{2}$ lebar balok maka tinggi balok $=\frac{1}{2} \times 10 \mathrm{~cm}=5 \mathrm{~cm}$. Siswa tidak menuliskan kesimpulan pertanyaan soal.

Hasil analisis menunjukkan bahwa terdapat perbedaan antara nilai rata-rata kelas eksperimen dengan model pembelajaran problem posing tipe within solution posingdan nilai rata-rata kelas kontrol dengan metode ekspositori yaitu, 66,41 untuk kelas eksperimen dan 56,82 untuk kelas kontrol.

Nilai maksimum kelas eksperimen lebih tinggi dari nilai maksimum kelas kontrol, yaitu 91 untuk kelas ekperimen dan 79 untuk kelas kontrol. Untuk nilai minimum pada kelas eksperimen yaitu 30 dan nilai minimum kelas kontrol yaitu 37. Nilai rata-rata kelas eksperimen lebih tinggi dari kelas kontrol, yaitu 66,41 dan untuk kelas kontrol yaitu 56,82. Hal ini berarti terdapat perbedaan hasil belajar antara kelas eksperimen dan kelas kontrol. Maka terdapat pengaruh dari model pembelajaran problem posingtipe within soluion posingterhadap hasil belajar siswa.

\section{PENUTUP \\ Simpulan}

Berdasarkan hasil penelitian yang telah dilakukan diperoleh nilai rata-rata posttest hasil belajar kelas eksperimen adalah 66,41 dan nilai rata-rata posttest hasil belajar kelas kontrol adalah 56,82. Dari hasil posttest tersebut kemudian dilakukan pengujian statistik dengan Sig. $=0,02$ dengan taraf nyata $\alpha=10 \%$, Didapat bahwa Sig. $<\alpha$ yaitu $0,02<0,1$ maka $H_{0}$ ditolak. Sehingga $\mathrm{H}_{1}$ diterima artinya ratarata hasil belajar matematika siswa antara model pembelajaran problem posing tipe within solution posing lebih tinggi dari hasil belajar matematika siswa dengan pembelajaran ekspositori di kelas VIII SMP Negeri 13 Kota Bengkulu. Oleh karena itu, dapat disimpulkan bahwa terdapat pengaruh hasil belajar peserta didik yang menggunakan model pembelajaran problem posing tipe within solution 
posingterhadap hasil belajar matematika siswa di SMP Negeri 13 Kota Bengkulu.

\section{SARAN}

Saran yang dapat dikemukakan berdasarkan hasil penelitian yang telah dilaksanakan adalah:

1. Guru sebaiknya mengingatkan dan mengecek setiap kelompok peserta didik agar mengerjakan lembar soal sesuai dengan petunjuk soal yang diberikan.

2. Sebaiknya dalam menerapkan model pembelajaran problem posing tipe within solution posing, guru memberikan contoh pengerjaan soal sesuai model problem posing tipe wihtin solution posing terlebih dahulu kepada siswa.

3. Guru dalam menerapkan model pembelajaran problem posing selalu mengingatkan peserta didik untuk melibatkan semua anggota kelompok pada saat diskusi kelompok baik dalam pembuatan soal maupun menyelesaikan soal pada Lembar Soal.

\section{DAFTAR PUSTAKA}

Dahar, Ratna Wilis. 2011. Teori-teori Belajar dan Pembelajaran. Bandung: Erlangga.

Dimyati dan Mudjiono. 2013. Belajar dan Pembelajaran. Jakarta: Rineka Cipta.

Guntara, I Wayan dkk. 2014. Pengaruh Model Pembelajaran Problem Posing Terhadap Hasil Belajar Matematika di SD Negeri Kalibukbuk. E-Journal Mimbar PGSD. Vol.2,No.1.

Jihad, Asep dan Abdul Haris. 2013. Evaluasi Pembelajaran. Yogyakarta: Multi Pressindo.

Lestari dan Yudhanegara. 2017. Penelitian pendidikan Matematika. Bandung : PT Refika Aditama

Majid, Abdul. 2013. Srategi Pembelajaran. Bandung: PT Remaja Rosdakarya.

Sudjana, Nana. 2016. Penilaian Hasil Proses Belajar Mengajar. Bandung: Remaja Rosdakarya.

Sugiyono. 2017. Statistik untuk Penelitian. Bandung : Alfabeta
Taufik, Taufina dan Muhammadi. 2011. Mozaik Pembelajaran Inovatif. Padang: Sukabina Press.

Thobroni, M. 2016. Belajar \& Pembelajaran. Yogyakarta: Ar-ruzz Media. 